\title{
Asthma relieved by aspirin and by other cyclo-oxygenase inhibitors
}

\author{
A SZCZEKLIK, R J GRYGLEWSKI, AND E NIŻANKOWSKA \\ From the Departments of Allergy and Clinical Immunology, and of Pharmacology, \\ Copernicus Academy of Medicine, Cracow, Poland
}

Some patients with bronchial asthma report that aspirin decreases their shortness of breath. We describe an asthmatic patient in whom airways obstruction could be reversed effectively by aspirin and by several other cyclo-oxygenase inhibitors, that is, analgesics that suppress the generation of prostaglandins (PG), thromboxane $\mathrm{A}_{2}\left(\mathrm{TXA}_{2}\right)$, and prostacyclin $\left(\mathrm{PGI}_{2}\right)$ in the tissues.

\section{Case report}

A 62-year-old man had been well until 10 years previously when he experienced a first attack of dry cough. Coughing continued and four years before admission, after a flu-like illness, attacks of breathlessness and wheezing began to occur. Though treated with bronchodilators and prednisone he noticed that asprin relieved his symptoms and began to take it regularly. The frequency and severity of attacks of cough and dyspnoea diminished, and the steroid dose could be reduced by half. Diabetes and extrapyramidal tremor, diagnosed a few years before admission, were controlled well by diet and trihexyphenidyl respectively. Two years before admission, prednisone was replaced by triamcinolone and petechiae over the forearms appeared.

The patient was a dyspnoeic man with petechiae over both forearms, vitiligo on the forehead and abdomen, and signs of pulmonary overinflation. Routine laboratory test results were within normal limits. Skin tests with common aeroallergens gave negative results. His airways obstruction was partially reversed by isoprenaline. The tourniquet test result was positive. Bleeding, clotting, prothrombin, partial thromboplastin, and euglobulin lysis times, as well as platelet count, fibrinogen, and fibrin degradation product levels, were all within the normal range. Results of the following platelet function studies, performed as described previously (Szczeklik et al, 1978) were normal: aggregation thresholds both to arachidonic acid and ADP, generation of thromboxane $\mathrm{A}_{2}$ by platelet-rich plasma, and inhibition of aggregation by aspirin and nictindole.

Six non-steroidal anti-inflammatory drugs and placebo were taken in gelatin capsules, and clinical symptoms and peak expiratory flow rate (PFR) were checked every $60 \mathrm{~min}$ over the following eight hours. Only one drug or placebo was given on any one day. The initial PFR values during the tests were in the range of $30-50 \%$ of predicted. Aspirin $(600 \mathrm{mg})$, indomethacin $(40 \mathrm{mg})$, fenoprofen $(200 \mathrm{mg})$, and mefenamic acid $(75 \mathrm{mg})$ all increased PFR values by $40-75 \%$. These effects occurred about one hour after ingestion of the drug, lasted several hours, and were accompanied by a considerable relief of dyspnoea and decrease of wheezes heard over the lungs. Salicylamide $(1.0 \mathrm{~g})$, benzydamine $(1.0 \mathrm{~g})$, and placebo had no effect on either PFR or clinical symptoms. The detailed studies of the influence of aspirin on lung

Table Effect of aspirin on lung function. Measurements were taken initially and 90 min after placebo. Then $1 \cdot 2 \mathrm{~g}$ aspirin was taken and pulmonary function tests were recorded 90 and 135 minutes later

\begin{tabular}{|c|c|c|c|c|c|}
\hline Pulmonary tests & $\begin{array}{l}1000 \\
\text { (Initial values) }\end{array}$ & $\begin{array}{l}1130 \\
\text { (After placebo) }\end{array}$ & $\begin{array}{l}1300 \\
(\text { After } 1 \cdot 2 \mathrm{~g} \text { aspirin })\end{array}$ & 1345 & Predicted values \\
\hline 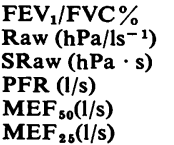 & $\begin{array}{c}65 \\
15 \cdot 4 \\
107 \cdot 6 \\
3 \cdot 0 \\
0 \cdot 8 \\
0 \cdot 35\end{array}$ & $\begin{array}{l}60 \\
14 \cdot 4 \\
92 \cdot 2 \\
2 \cdot 72 \\
0 \cdot 8 \\
0 \cdot 4\end{array}$ & $\begin{array}{c}70 \\
2.9 \\
14 \cdot 0 \\
4 \cdot 55 \\
2 \cdot 3 \\
0 \cdot 85\end{array}$ & \begin{aligned} \multicolumn{1}{l}{76} \\
2.8 \\
13.0 \\
$5 \cdot 3 \\
1.9 \\
0.6\end{aligned}$ & $\begin{array}{l}70 \\
1 \cdot 8 \\
7 \cdot 5 \\
9 \cdot 6 \\
4 \cdot 4 \\
2 \cdot 1\end{array}$ \\
\hline
\end{tabular}

$\mathrm{FEV}_{1} / \mathrm{FVC} \%=$ Forced expiratory volume 1 second in per centage of forced vital capacity; $R$ Raw = Airway resistance; SRaw $=$ Specific airway

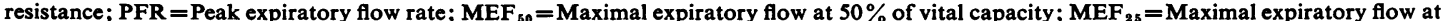
$25 \%$ of vital capacity; $0.98 \times \mathrm{hPa}=\mathrm{cm} \mathrm{H}_{2} \mathrm{O}$. 
function are presented in the table. The patient was restudied four months later, and the results with analgesics were very much the same.

\section{Comment}

Airways obstruction was strikingly relieved by aspirin in the patient studied. Similar beneficial effects were produced by three other cyclooxygenase inhibitors, that is, by indomethacin, mefenamate, and fenoprofen, but not by two remaining analgesics-salicylamide and benzydamine-which do not inhibit PG biosynthesis (Vane, 1976; Szczeklik et al, 1977). It was, therefore, logical to assume that the pharmacological removal of a product of arachidonic acid (AA) cyclooxygenation from his respiratory tract helped our patient to overcome the airways obstruction. Perhaps this product was a bronchoconstrictor $\mathrm{PGF}_{2} \alpha$, $\mathrm{TXA}_{2}$, or other as yet unknown metabolite. Whatever the metabolite was, it could not have been a physiological one, since we have found that bronchodilator $\mathrm{PGI}_{2}$ and $\mathrm{PGE}_{2}$ are two major products of AA transformation in the lungs (Gryglewski et al, 1978).

In our patient the suspected abnormality in arachidonate metabolism was restricted to the respiratory system. Detailed platelet function studies, particularly those related to arachidonic pathway, failed to show any differences from the normal. The transient petechiae were most likely due to increased vascular fragility secondary to triamcinolone administration.

The number of asthmatic patients who might benefit from aspirin is not known. Trial of aspirin treatment might seem warranted in asthma, since it could allow the steroid dose to be reduced, as in our case. Great care, however, would be necessary at the beginning of such treatment, and the initial dose of aspirin should not exceed $20-40 \mathrm{mg}$, as the same cyclo-oxygenase inhibitors, which proved to be so efficient in relieving bronchoconstriction in our patient, may produce bronchoconstriction in other asthmatics suffering from socalled aspirin-induced asthma (Szczeklik et al, $1975 ; 1977)$. Thus two opposite reactions can be caused in asthmatics by the same specific inhibitors. This indicates that different mediators, even derived from the same precursor, might play a different role in various types of asthma.

\section{Discussion}

Gryglewski, R J, Korbut, R, Ocetkiewicz, A (1978). Generation of prostacyclin by lungs in vivo and its release into arterial circulation. Nature, 273, 765767.

Szczeklik, A, Gryglewski, R J, and CzerniawskaMysik, G (1975). Relationship of inhibition of prostaglandin biosynthesis by analgesics to asthma attacks in aspirin-sensitive patients. British Medical Journal, 1, 67-69.

Szczeklik, A, Gryglewski, R J, and CzerniawskaMysik, G (1977). Clinical patterns of hypersensitivity to nonsteroidal anti-inflammatory drugs and their pathogenesis. Journal of Allergy and Clinical Immunology, 60, 276-284.

Szczeklik, A, Gryglewski, R J, Musial, J, Grodzińska, L, Serwońska, M, and Marcinkiewicz, E (1978). Thromboxane generation and platelet aggregation in survivals of myocardial infarction. Thrombosis and Haemostasis. (In press.)

Vane, J R (1976). The mode of action of aspirin and similar compounds. Journal of Allergy and Clinical Immunology, 58, 691-704.

Requests for reprints to: Dr A Szczeklik, Copernicus Academy of Medicine, Skawińska 8, 31-066 Cracow, Poland.

\section{Corrections}

1 Warren, C P W et al. Mechanical properties of the lung in extrinsic allergic alveolitis. Thorax, 1978, $33,315-321$.

The caption to figure 1 should show (a) four weeks and (b) one week.

2 Battesti, V P et al. Chronic cor pulmonale in pulmonary sarcoidosis. Thorax, 1978, 33, 76-84.

The authors regret that they omitted to acknowledge Professor J Turiaf, who originally studied the patients. 